\title{
INTENÇÃO, POLIDEZ \\ E RELEVÂNCIA ENUNCIATIVA: \\ GRAMATICALIZAÇÃO \\ NA CONSTRUÇÃO \\ QUERER+INFINITIVO \\ EM LÍNGUA ESPANHOLA
}

\section{INTENCIÓN, CORTESÍA Y RELEVANCIA ENUNCIATIVA: GRAMATICALIZACIÓN DE LA CONSTRUCCIÓN QUERER+INFINITIVO EN LENGUA ESPAÑOLA}

\author{
INTENTION, POLITENESS AND ENUNCIATIVE RELEVANCE: GRAMMATICALIZATION OF \\ THE CONSTRUCTION QUERER+INFINITIVE IN SPANISH LANGUAGE
}

André Silva Oliveira*

Nadja Paulino Pessoa Prata**

Universidade Federal do Ceará

\begin{abstract}
RESUMO: O presente trabalho tem por objetivo a descrição e análise da construção querer+infinitivo, tendo por base o processo de gramaticalização no Componente Gramatical (HENGEVELD, 2017). Para isso, constituímos um córpus com base nos discursos de investidura de dois candidatos a primeiro ministro do governo espanhol. Em termos gerais, verificamos que a construção querer+infinitivo opera tanto na camada da Propriedade Configuracional (Nível Representacional), funcionando como um modalizador volitivo, sendo empregada para manifestar as intenções do falante; quanto na camada do Ato Discursivo (Nível Interpessoal), em que atua como um elemento discursivo ao expressar polidez e cortesia ou na manifestação da relevância enunciativa daquilo que a construção escopa a partir do contexto de interação.
\end{abstract}

PALAVRAS-CHAVE: Gramaticalização. Volição. Polidez e Cortesia. Querer+infinitivo.

RESUMEN: El presente trabajo tiene como objetivo hacer un análisis de la construcción querer+infinitivo, teniendo como base el proceso de gramaticalización en el Componente Gramatical (HENGEVELD, 2017). Para ello, constituimos un corpus a partir de los discursos de investidura de dos candidatos a primer ministro del gobierno español. En términos generales, verificamos que la construcción querer+infinitivo opera tanto en la camada de la Propiedad Configuracional (Nivel Representativo), funcionando

\footnotetext{
* Doutorando em Linguística pelo Programa de Pós-Graduação em Linguística da Universidade Federal do Ceará (PPGL/UFC). Integra o Grupo de Pesquisa em Funcionalismo (GEF), atuando na linha de descrição e análise da língua espanhola soboviés da perspectiva funcionalista. E-mail: andrethtzn@gmail.com.

** Doutora em Linguística. Professora do Departamento de Letras Estrangeiras da Universidade Federal do Ceará (DLE/UFC). Professora do Programa de Pós-Graduação em Linguística (PPGL/UFC). Vice-líder do Grupo de Pesquisa em Funcionalismo(GEF/UFC).E-mail:nadja.prata@gmail.com.
} 
como un modalizador volitivo para la expresión de las intenciones del hablante; como en la camada del Acto Discursivo (Nivel Interpersonal), en que actúa como un elemento discursivo, pasando a expresar cortesía o para actuar en la manifestación de la relevancia enunciativa de aquello que la construcción escopa a partir del contexto de interacción.

PALABRAS CLAVE: Gramaticalización. Volición. Cortesía. Querer+infinitivo.

ABSTRACT: The present work aims to make an analysis of the construction querer+ infinitive based on the grammaticalization process in the Grammatical Component (HENGEVELD, 2017). For this purpose, we constituted a corpus based on the investiture speeches of two candidates for prime minister of the Spanish government. In general terms, we verify that the querer+infinitive construct operates on both the Configurational Property layer (Representational Level)-, functioning as a volitive modalizer for the expression of the intentions of the speaker, and on the layer of the Discursive Act (Interpersonal Level), in which it acts as a discursive element by expressing politeness or to act in the manifestation of the enunciative relevance of what the construction takes as the scope from of the interaction context.

KEYWORDS: Grammaticalization. Volition. Politeness. Querer+infinitive.

\section{INTRODUÇÃO}

Ao fazermos uma reflexão sobre os diferentes usos da construção querer+infinitivo, é perceptível que essa construção esteja se gramaticalizando na língua espanhola, tendo em vista o tipo de verbo no infinitivo (performativo, cognitivo ou dicendi) que é utilizado pelos usuários da língua para essa construção morfossintática. Tradicionalmente, o verbo querer, segundo Gómez Torrego (2009), é visto como um verbo de volição, quando empregado apenas como verbo de significação plena. Quando empregado juntamente com outro verbo no infinitivo (formando uma construção perifrástica), poderia apresentar tanto seu valor semântico volitivo, como no exemplo: ${ }^{1}$ Juan no quiso trabajar [João não quis trabalhar] (GÓMEZ TORREGO, 2009, p. 98); quanto um valor volitivo debilitado ou mais afastado (aspectualidade), como no exemplo: Hoy quiere llover [Hoje quer chover] (GÓMEZ TORREGO, 2009, p. 99).

De acordo com Gramática da Real Academia Espanhola - GRAE (2010), a forma perifrástica querer+infinitivo assimila, parcialmente, as perífrases verbais, já que não integra todos os aspectos das estruturas perifrásticas já gramaticalizadas em língua espanhola, como: (i) a anteposição de pronome átono, como no exemplo: Quiero intentarlo [Quero tentá-lo] (GRAE, 2010, p. 534); (ii) a impossibilidade de passivização com o verbo ser "como sujeito de coisa", por exemplo: *Soluciones que no quisieron ser adoptadas [ ${ }^{*}$ Soluções não quiseram ser adotadas] (GRAE, 2010, p. 534); e (iii) o fato de o grupo do infinitivo alternar com subordinadas substantivas do verbo na forma pessoal e com grupos nominais, podendo coordenar com ambas as estruturas, como nos exemplos seguintes: Quiero [ir a su casa y que ustedes vengan a la mía]/Quiere [trabajar en el hospital y la licencia necesaria para hacerlo] [Quero (ir a sua casa e que vocês venham a minha casa)/[Quer (trabalhar no hospital e a licença necessária para isso)] (GRAE, 2010, p. 534).

Para a GRAE (2010), apenas os casos de imanência é que podem ser considerados como perifrásticos em relação ao verbo querer, como nos exemplos: Quiere llover/Te quieres enfermar [Quer chover/Você quer ficar doente] (GRAE, 2010, p. 534). Excetuando os casos de imanência (com os quais não pretendemos trabalhar, pois já se constituem casos de completa gramaticalização), optamos por analisar o emprego da forma perifrástica com o verbo querer apenas para os casos em que esse verbo estivesse acompanhado de verbos performativos, o que é um caso de modalidade volitiva com valor semântico de intenção, conforme Oliveira (2017); ou os casos em que o verbo querer venha acompanhado de algum verbo cognitivo e/ou dicendi, que seria uma marca de polidez e cortesia e não um caso de modalidade. Em termos específicos, a proposta deste artigo consiste em verificar aquilo que a construção querer+infinitivo toma como escopo, verificando a sua atuação nas camadas e nos níveis do Componente Gramatical, particularmente, nos Níveis Representacional e Interpessoal, de modo a analisar um possível processo de gramaticalização desta construção em língua espanhola, tendo em vista Hengeveld (2017).

${ }^{1}$ Ressaltamos que todas as traduções são livres e de total responsabilidade dos autores. 
Para a composição do nosso universo de investigação, selecionamos os discursos de investidura de Rodríguez Zapatero (candidato a primeiro ministro do governo espanhol nos anos de 2004 e 2008) e de Pedro Sánchez (candidato a primeiro ministro do governo espanhol no ano de 2016), em virtude da construção discursiva e da articulação da volitividade (elemento do desejo) no momento de interação com seus ouvintes (membros do Parlamento Espanhol) ao proferirem seus discursos de investidura. Em relação à análise quantitativo-qualitativa, utilizamos o Programa SPSS (Statistical Package for Social Science) para a rodagem dos dados, após a análise dos casos encontrados no córpus selecionado.

Para cumprir os objetivos pautados para este artigo, organizamo-lo da seguinte forma: (i) discorremos acerca do processo de gramaticalização com base em Hengeveld (2017); (ii) dissertamos sobre o emprego da construção querer+infinitivo em língua espanhola; (iii) apresentamos a descrição e a análise da construção querer+infinitivo nos discursos de investidura selecionados; e (iv) concluímos, o nosso artigo com base no que foi analisado acerca da construção querer+infinitivo.

\section{O PROCESSO DE GRAMATICALIZAÇÃO NO QUADRO TEÓRICO DA GRAMÁTICA DISCURSIVO-FUNCIONAL}

O processo de gramaticalização está relacionado a mudanças que ocorrem nas línguas naturais, em que formas lexicais passam a funcionar como elementos gramaticais dentro do sistema linguístico ou elementos já gramaticalizados passam a exercer novas funções gramaticais. Para Furtado da Cunha (2009, p. 173), a gramaticalização constitui um processo em que "itens lexicais ou construções sintáticas, em determinados contextos, passam a assumir novas funções gramaticais e, uma vez gramaticalizados, continuam a desenvolver novas funções”. Dessa forma, segundo Barreto e Souza (2016), entende-se que, nos processos de gramaticalização, há uma integração dos componentes da linguagem, ou seja, há uma inter-relação entre a pragmática, a semântica e a sintaxe que, em conjunto, permitem que o falante engendre as sentenças da língua em conformidade com as suas necessidades comunicativas. Essa mesma posição também é assumida na Gramática Discursivo-Funcional (GDF), de Hengeveld e Mackenzie (2008, p. 2), em que os autores dizem "a GDF oferece uma descrição autônoma e equilibrada dos aspectos pragmáticos, semânticos e morfossintáticos para a forma linguística".

Para a teoria da GDF, temos que a pragmática governa a semântica, ambas regem a morfossintaxe, e as três agenciam a fonologia. Para a GDF, a pragmática, a semântica, a morfossintaxe e a fonologia dispõem-se, no Componente Gramatical, de forma hierárquica, distribuídas em níveis de análise linguística, em um modelo de gramática que é entendido como top-down, em que os elementos dos níveis e camadas superiores influenciam os níveis e as camadas inferiores. De acordo com Hengeveld e Mackenzie (2008), a interação entre os componentes pragmáticos, semânticos e morfossintáticos podem influenciar nos processos de mudança linguística, provocando alterações semânticas, morfossintáticas e fonológicas. Essas alterações podem conduzir os elementos linguísticos, que ainda se encontram a nível lexical ou que já estejam gramaticalizados, a se gramaticalizarem (ou se gramaticalizarem ainda mais) na língua, ampliando seu escopo de atuação dentro da gramática.

De acordo com Souza (2009) e Casseb-Galvão (2011), a GDF não explicita mecanismos mais específicos para o fenômeno da gramaticalização, restringindo-se apenas a expor alguns mecanismos que antes apresentavam alguma função linguística e que, com o uso, passam a desempenhar outras funções como elementos reportativos, modais ou evidenciais. Resumidamente, temos que o modelo da GDF, ao diferenciar níveis e camadas, prevê a possibilidade de categorias conceituais e níveis para os quais se possam prever categorias gramaticais e discursivas relevantes. Segundo os autores, a teoria da GDF tem-se mostrado, nesse aspecto, favorável à descrição e análise dos processos de gramaticalização, que se caracterizam, de acordo com Casseb-Galvão (2011, p. 318), como "desenvolvimento de itens ou construções conceituais ou mais ou menos conceituais (mais concretos) em itens ou construções gramaticais, mais gramaticais ou em elementos de valor discursivo (mais abstratos)".

Para Casseb-Galvão (2011, p. 318-319), há alguns pontos no aparato teórico da GDF que contribuem para o entendimento do processo de gramaticalização, tais como: (i) a existência de níveis de representação relevantes para a construção de enunciados que serão usados na produção desses mesmos enunciados. Dessa forma, é possível que as línguas naturais apresentem conexões diretas de um nível a outro do Componente Gramatical; (ii) o reconhecimento de que há uma inter-relação dinâmica entre os níveis que compõem o Componente Gramatical e no que se refere às operações de Formulação e de Codificação, em que o dinamismo 
linguístico pressupõe que haja alterações a nível pragmático e semântico, levando também a alterações no Nível Morfossintático e no Nível Fonológico; (iii) a previsão de uma ordenação hierárquica unidirecional interníveis e intraníveis de organização, já que a estrutura top-down aplica-se as camadas constitutivas desses níveis. O reconhecimento da unidirecionalidade é um recurso fundamental na análise dos dados retirados do uso de um dado item linguístico em processo de gramaticalização, haja vista que a partir dos dados analisados que se pode comprovar se o item lexical está ou não em processo de gramaticalização; e (iv) o reconhecimento de uma categorização em contínuo, isto é, não se trabalha, na GDF, com categorias discretas. Para isso, a GDF recorre à noção de protótipo $^{2}$ para que se diferenciem os elementos que modificam e elementos que especificam as variáveis nas camadas, respectivamente, modificadores (de natureza lexical) e operadores (de natureza gramatical).

Segundo Souza (2009), os processos de gramaticalização começam no Nível Representacional, passando pelas camadas que compõem esse nível (com suas categorias semânticas), indo em direção das camadas que compõem o Nível Interpessoal (com suas categorias pragmáticas). Complementando o que foi dito por Souza (2009) e Casseb-Galvão (2011), Barreto e Souza (2016) diz que a gramaticalização, dentro do aparato teórico da GDF, é vista como um processo em que as formas linguísticas expandem-se, funcionalmente, entre as camadas e os níveis do Componente Gramatical (em que se encontram o Nível Interpessoal, o Nível Representacional, o Nível Morfossintático e o Nível Fonológico), obedecendo, no entanto, a organização hierárquica da linguagem. Dessa forma, o autor acrescenta que, uma vez iniciado o processo de gramaticalização de algum item lexical ou de um item já gramaticalizado, este item percorre primeiro as camadas mais baixas, indo em direção às camadas mais altas do Nível Representacional (que está relacionado aos aspectos semânticos da linguagem). Depois de percorridas as camadas do Nível Representacional, espera-se que esse mesmo item percorra as camadas mais baixas até chegar às camadas mais altas do Nível Interpessoal (que está relacionado com os aspectos pragmáticos). O autor ainda acrescenta que, uma vez que esse item (em processo de gramaticalização) tenha alcançado as camadas mais altas do Componente Gramatical, é impossível que ele retorne às camadas e aos níveis mais baixos desse mesmo componente.

Segundo Hengeveld (2017), nos processos de gramaticalização, tanto o significado quanto a forma de um dado elemento linguístico podem sofrer mudança, ainda que essa mudança não se produza de forma simultânea. $O$ autor entende que, no processo de gramaticalização, que começa quando um elemento lexical entra no sistema gramatical, as mudanças levam a um aumento do escopo semântico-pragmático de atuação do elemento linguístico que se gramaticaliza, em que o aumento desse escopo pode ser aplicado a partir de três formas diferentes: (i) apenas dentro do Nível Representacional; (ii) apenas dentro do Nível Interpessoal; e (iii) do Nível Representacional para o Nível Interpessoal. Segundo o autor, as unidades semânticas se desenvolvem, diacronicamente, das camadas mais baixas para as camadas mais altas dentro do Nível Representacional.

Dessa forma, a gramaticalização de um dado elemento que entra no sistema gramatical da língua, ao considerarmos apenas os aspectos semânticos (Nível Representacional), ocorre ao longo da seguinte via, como vemos no Quadro 1:

$$
\begin{gathered}
\text { Proposição }<\text { Episódio }<\text { Estado-de-Coisas }<\text { Propriedade Configuracional } \leftarrow \text { Propriedade Lexical } \\
\text { Quadro 1: Processo de gramaticalização dentro do Nível Representacional da GDF } \\
\text { Fonte: Traduzido de Hengeveld }(2017, \text { p. 5) }
\end{gathered}
$$

Segundo Hengeveld (2017), a GDF prevê também gramaticalização ocorrendo apenas dentro do Nível Interpessoal (considerando apenas os aspectos pragmáticos). Dessa forma, têm-se que as unidades pragmáticas, desenvolvendo-se diacronicamente, percorrem as camadas mais baixas, indo em direção às camadas mais altas. Em termos das camadas que compõem o Nível Interpessoal, o processo de gramaticalização ocorre ao longo da seguinte via, como vemos no Quadro 2:

Ato Discursivo $\leftarrow$ Ilocução $\leftarrow$ Conteúdo Comunicado $\leftarrow$ Subato de Referência $\leftarrow$ Subato de Atribuição

Quadro 2: Processo de gramaticalização dentro do Nível Interpessoal da GDF

Fonte: Traduzido de Hengeveld (2017, p. 7)

\footnotetext{
${ }^{2}$ Em Hengeveld e Mackenzie (2008, p. 134), o conceito de protótipo é entendido como nominalização, referindo-se “à designação de classes sistemáticas que são tratadas no sistema morfológico de uma língua”. Dentro da perspectiva funcionalista, Givón (2001, p. 32) define o protótipo como a “[...] categoria que exibe o maior número de propriedades ou características dessa categoria”.
} 
Para Hengeveld (2017), as unidades semânticas podem se desenvolver, diacronicamente, em unidades pragmáticas (fenômeno apenas unidirecional, ou seja, dá-se apenas dos níveis e camadas inferiores para os níveis e camadas superiores). Nesse caso, há um aumento do escopo semântico-pragmático no sentido vertical, isto é, no sentido de que os elementos pertencentes às camadas mais baixas do Nível Representacional desenvolvam-se em direção às camadas mais altas do Nível Interpessoal, como ilustrado no Quadro 3:

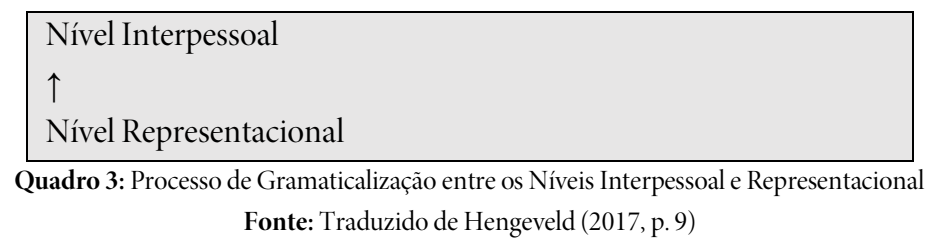

Hengeveld (2017) argumenta que um dado item linguístico, em processo de gramaticalização, não precisa percorrer todas as camadas do Nível Representacional para chegar às camadas do Nível Interpessoal e, ao chegar a este nível, que percorra, necessariamente, todas as camadas que o compõem, já que esse item linguístico pode percorrer os níveis a partir de qualquer posição intermediária.

Como pretendemos analisar os possíveis casos de gramaticalização da construção querer+infinitivo, apresentamos, na seção seguinte, como essa forma perifrástica se comporta em língua espanhola, já que, geralmente, é empregada para modalizar enunciados relacionados ao que é desejável ao falante (modalidade volitiva), em que o falante expressa a intencionalidade de potencializar um dado evento (prospectivo), ou seja, o valor semântico da volição está relacionado a um evento volitivo, cuja realização se dará em um momento posterior ao momento de fala ${ }^{3}$.

\section{O EMPREGO DA CONSTRUÇÃO QUERER+INFINITIVO EM LÍNGUA ESPANHOLA}

Existe, em língua espanhola, a possibilidade de fazermos referência a um momento posterior ao da enunciação por meio de diferentes formas, tais como o futuro simples, o emprego da forma perifrástica ir $+a+$ infinitivo ou pela utilização do presente do indicativo, especificamente, por meio de alguma forma modal. Nessas formas, estão inclusos também alguns verbos (modalizadores), como pretender, desear, intentar, pensar, apetecer e querer. Segundo Martínez, Manzano e Barriendos (2004), para a expressão de futuridade, geralmente, as formas modais costumam vir acompanhadas de verbos no infinitivo, estando algumas dessas formas ainda pouco gramaticalizadas na língua espanhola, como pensar+infinitivo, pretender+infinitivo, desear+infinitivo e querer+infinitivo, pois ainda funcionam como verbos léxicos, mas de caráter modal; enquanto outras formas já se encontram mais gramaticalizadas, como ir+a+infinitivo, em que há um esvaziamento semântico do verbo auxiliar, que designa em sua origem, deslocamento, e que, ao se gramaticalizar, passa a designar alguma intenção ou prospecção futura. Especificamente, em relação à construção querer+infinitivo, não se pode falar ainda em completa gramaticalização, tendo em vista que, em língua espanhola, o verbo querer, conforme Hidalgo (2012), ainda acarreta ao enunciado modalizado seu sentido de volição, apresentando, pois, apenas um efeito prospectivo esporádico, já que não incorpora, completamente, um valor modal e outro temporal para a expressão da futuridade.

De acordo com Alconchel (2004), a construção querer+infinitivo pode apresentar o valor de disposição (intenção) ou o valor de possibilidade. Para o valor semântico de intenção, o falante descreve as suas intencionalidades em relação a um evento prospectivo. Conforme Topor (2011), a língua espanhola apresenta uma série de perífrases verbais, já gramaticalizadas, para a expressão das

\footnotetext{
${ }^{3}$ Dentro do aparato teórico da GDF, a modalidade volitiva está relacionada ao que é desejável (domínio semântico), podendo estar, conforme a orientação modal, a saber: (i) orientada-para-o-participante, que descreve o desejo do participante expresso no predicado em realizar aquilo que lhe é desejável; (ii) orientada-para-oevento, que caracteriza um dado evento como algo desejável, mas sem que haja um comprometimento por parte do falante em relação ao estado-de-coisas apresentado; e (iii) orientada-para-a-proposição, está relacionada com a afirmação dos desejos pessoais do falante em relação ao estado-de-coisas apresentado, sendo apenas localizado na mente do falante e realizável apenas no ponto de vista não-factual.
} 
intenções do falante, tais como: pensar+infinitivo, ir+a+infinitivo, estar+por+infinitivo, tratar + de+infinitivo, venir $+a+i n f i n i t i v o$, haber+de+infinitivo, etc., como nos exemplos respectivamente: Pienso comprar terrenos/Voy a denunciar a los ladrones/Mira lo que te digo, estoy por irme y no volver más/Trató de ayudarnos/¿Qué vienes a hacer aquí?/Cuando vuelvas por la tienda, he de darte los catálogos [Estou pensando em comprar terrenos/Vou denunciar os ladrões/Escuta o que te digo, estou indo para não mais voltar/Tratou de nos ajudar/O que você veio fazer aqui?/Quando você voltar da loja, eu vou dar a você os catálogos] (TOPOR, 2011, p. 179).

Para Hidalgo (2012), o emprego da construção querer+infinitivo permite que o falante estabeleça um vínculo inferencial com o evento futuro, especificamente, de posterioridade (futuro prospectivo esporádico) por meio do prisma de uma modalidade atual, referindo-se a um estado de volição. Para esse autor, o uso da construção querer+infinitivo está relacionado, na maioria das ocorrências em língua espanhola, com a intenção do sujeito em realizar uma atividade expressa por meio do verbo no infinitivo na posição de complemento, ou seja, aquilo que o verbo querer toma como escopo, refere-se a uma desejabilidade de potencialização do estado-de-coisas expresso na proposição. Por isso, para ele, não se pode falar que, em forma perifrástica, o verbo querer funcione como um verbo auxiliar, como ocorre com perífrases já gramaticalizadas na língua espanhola, tais como ir $+a+i n f i n i t i v o$, estar+gerúndio, tener+que+infinitivo, etc., mas como um verbo pleno, como no exemplo: Los jueces quieren detener a los delincuentes [Os juízes querem prender os delinquentes] (HIDALGO, 2012, p. 149). Por isso, preferimos denominar construção perifrástica, por se apresentar em forma de perífrase (TOPOR, 2011; HIDALGO, 2012), a definir o querer+infinitivo como perífrase no sentido stricto sensu. No entanto, ainda conforme Hidalgo (2012), alguns quesitos poderiam contribuir para que essa construção perifrástica pudesse ser considerada como uma perífrase.

De acordo com Hidalgo (2012), a combinação dos pronomes clíticos com a construção querer+infinitivo poderia ser um indicativo de gramaticalização na língua espanhola, passando a funcionar como uma perífrase para expressar intencionalidade, como nos exemplos: Juan quiere leer ese libro/Juan quiere leerlo/Juan lo quiere leer [João quer ler esse livro/João quer lê-lo/João o quer ler] (HIDALGO, 2012, p. 150). A possibilidade de combinação com os pronomes clíticos tratar-se-ia de um indicativo de gramaticalização do querer, que deixaria de funcionar como um verbo pleno (verbo léxico) e passaria a se tornar um verbo auxiliar, gramaticalizando-se na língua espanhola para sinalar as intenções do falante.

Conforme Hidalgo (2012), outro aspecto relevante para que se possa considerar a construção querer+infinitivo como uma perífrase, deve-se ao fato de que um auxiliar modal admite o apagamento do sintagma verbal que toma como complemento, diferentemente, dos verbos principais. De acordo com esse critério, a construção querer+infinitivo, ao ser empregada para manifestar as intenções do falante, seguiria o padrão de um verbo auxiliar, como no exemplo: Juan quiere bailar, pero María (no quiere/ ${ }^{*}$ no lo quiere) [João quer dançar, mas Maria (não quer ${ }^{*}$ não o quer)] (HIDALGO, 2012, p. 150). Nesse sentido, poderíamos inferir para esses casos, que o querer, quando acompanhado de verbo no infinitivo, poderia ser classificado como um verbo auxiliar e a construção em seu conjunto, querer+infinitivo, como uma perífrase verbal.

Ainda segundo o autor, um dos indícios de gramaticalização da construção querer+infinitivo seria o emprego dela para manifestar valores de iminência, como no exemplo: El sol quiere apuntar [O sol quer nascer] (HIDALGO, 2012, p. 150). Nesse exemplo, temos um caso de aspectualidade, e não de modalidade, em que o falante expressa apenas a ideia de que "o nascer do sol se aproxima". Para os casos de modalidade, o emprego da construção querer + infinitivo faz referência a estado-de-coisas futuros mediante a ancoragem modal em algum tempo no presente, em que a utilização do querer+infinitivo expresse a intencionalidade do falante (localizada no momento da enunciação) em relação a um evento que tenha lugar em um momento posterior ao da enunciação.

Com base em Hidalgo (2012), a forma perifrástica querer+infinitivo estaria em processo de gramaticalização, mas ainda guardaria seu sentido de volição, quando se pretende marcar alguma intencionalidade ou a pretensão de realização de um dado estado-decoisas.

De acordo com Sousa (2017), o percurso de gramaticalização de um verbo dá-se da seguinte forma: primeiramente, o verbo é empregado pelo falante com toda a sua carga semântica, ou seja, funciona como um verbo pleno; posteriormente, o verbo começa a combinar-se, no uso, a outros verbos, fazendo com que ele atue como um verbo semiauxiliar; para, em seguida, funcionar apenas 
como um verbo auxiliar, em que ocorre um esvaziamento do valor semântico do verbo agora já gramaticalizado, passando a forma uma única unidade com o verbo principal. Isso pode ser sintetizado no Quadro 4:

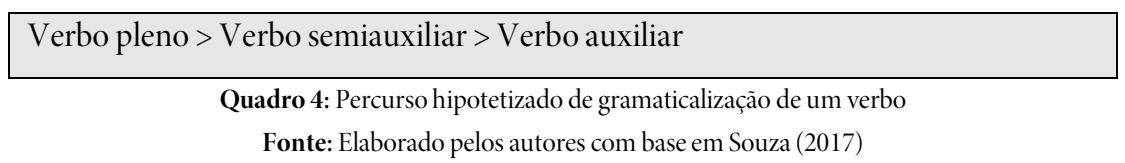

De acordo com Topor (2011), o conceito de verbo semiauxiliar aplica-se aos casos em que um dado verbo, dependendo do contexto em que apareça, funcione como um auxiliar perifrástico ou como verbo léxico, em que os verbos semiauxiliares apresentam um comportamento mediano entre os verbos léxicos e os auxiliares, haja vista que cumprem as características próprias de ambas as classes de verbos. Por isso, os verbos semiauxiliares podem aparecer sozinhos, sem o segundo verbo que os acompanha (os casos de omissão do segundo verbo, aproximando-os dos verbos léxicos) ou podem aparecer seguidos de outros verbos, mas sem que haja a possibilidade de comutação do verbo que o segue por outro elemento equivalente (o que os aproxima dos verbos auxiliares).

De acordo com Hidalgo (2012, p. 120), o verbo querer apresenta ambas as características, a depender do contexto, como nos exemplos (1) e (2):

(1) Juan quiere cantar una canción

(2) El sol quiere apuntar

Em (1), aquilo que o verbo querer toma como escopo pode ser comutado, por exemplo, por um pronome demonstrativo, no caso, eso [isso]: Juan quiere eso; o que não seria agramatical na língua espanhola; enquanto, em (2), aquilo que o verbo querer escopa, não poderia ser comutado, por exemplo, por esse pronome demonstrativo, pois a oração tornar-se-ia agramatical: ${ }^{\star} E l$ sol quiere eso. Em (1), temos um caso de modalização volitiva, em que há uma relação entre o participante expresso no predicado e o estado-de-coisas apresentado. Em (2), temos apenas um caso de aspectualidade, em que o verbo querer perde o seu valor volitivo, ainda que se empregue a construção perifrástica querer +infinitivo. Isso se deve em razão do tipo de sujeito ao qual o verbo querer está relacionado, sendo, no primeiro exemplo, um sujeito animado [+ humano] e capaz de volição; e, no segundo exemplo, um sujeito não animado [- humano] e, portanto, incapaz de volição, fazendo com que o querer perca as suas propriedades semânticas de volição e se enquadre nos casos de aspectualidade.

De acordo com Souza (2017), o desenvolvimento no campo modal em relação ao processo de gramaticalização de um dado modalizador, como, por exemplo, o modal querer, dá-se do mais concreto para o mais abstrato, havendo, portanto, um aumento gradual de subjetividade. Em outras palavras, seguindo a teoria da GDF, ao atuar em camadas mais baixas, o modalizador incide sobre algo mais objetivo, mais concreto, podendo ser localizado no tempo e no espaço; e, ao atuar em camadas mais altas, o modalizador incide sobre significados mais abstratos, mais subjetivos, pautados nas crenças e opiniões do falante. Vejamos o Quadro 5:

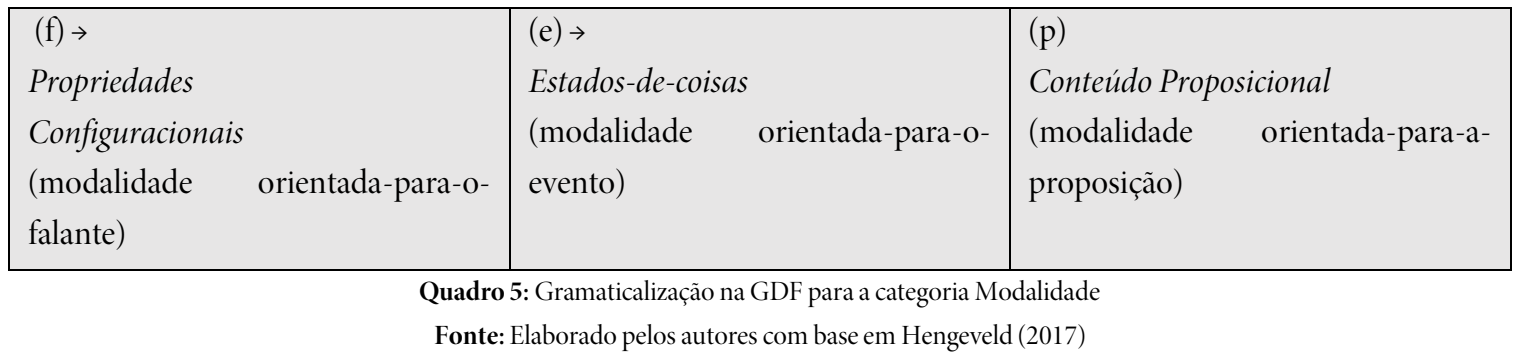

Em relação ao emprego da construção querer+infinitivo nos discursos de investidura, passemos agora a sua descrição e análise com base no Componente Gramatical, especificamente, em relação aos Níveis Interpessoal e Representacional na seção seguinte. 


\section{METODOLOGIA}

Para a descrição e análise da construção querer+infinitivo em língua espanhola, optamos pelos discursos de investidura ${ }^{4}$ de dois candidatos a primeiro ministro do governo espanhol. Os discursos de investidura foram retirados de websites on-line e foram analisados em sua totalidade no intuito de averiguar as ocorrências da construção querer+infinitivo no córpus elaborado para esta pesquisa. Após a análise do córpus, recorremos ao arcabouço teórico da GDF de Hengeveld e Mackenzie (2008) e ao trabalho de Hengeveld (2017) sobre o processo de gramaticalização dentro da GDF. Para a análise quantitativo-qualitativa, utilizamos o SPSS (Statistical Package for Social Science) para a rodagem da frequência dos dados.

Vejamos o Quadro 6:

\begin{tabular}{|c|c|c|}
\hline Discursos de Investidura & Data & Quantidade de Palavras \\
\hline Rodríguez Zapatero (D1) & 15 de abril de 2004 & 7.700 \\
\hline Rodríguez Zapatero (D2) & 08 de abril de 2008 & 9.360 \\
\hline Pedro Sánchez (D3) & 01 de março de 2016 & 12.820 \\
\hline Pedro Sánchez (D4) & 04 de março de 2016 & 2.250 \\
\hline Pedro Sánchez(D5) & 31 de agosto de 2016 & 5.790 \\
\hline Total de Palavras & & 37.920 \\
\hline
\end{tabular}

Os discursos de investidura, segundo Esteban (2011), são proferidos pelo candidato a primeiro ministro do governo espanhol. O candidato, buscando obter o apoio dos membros que compõem o parlamento espanhol, discursa acerca das suas pretensões políticas, não apenas daquilo que está obrigado a realizar em virtude de seu mandato, mas em relação ao que lhe parece bom, agradável e desejável para o país. Isso se dá, pois, segundo Álvarez e Chumaceiro (2009), os discursos de investidura pertencem ao gênero da comunicação política, correspondendo ao conjunto de textos oralizados, mas, previamente, escritos pelo candidato para serem articulados antes da realização das eleições. Com base em Oliveira, Nogueira e Prata (2017), escolhemos os discursos de investidura, tendo em vista que os candidatos a primeiro ministro discorrem a respeito do que lhe parece (in)desejável em termos de ações políticas previstas para o seu mandato, levando-a o fazer uso do verbo querer, como veremos na seção seguinte.

\section{DESCRIÇÃO E ANÁLISE DA CONSTRUÇÃO PERIFRÁSTICA QUERER+INFINITIVO}

Para a descrição e análise da construção querer+infinitivo, pautamos algumas categorias de análise, a saber: (i) o tipo de sujeito sintático/semântico que emprega a construção, ou seja, aquele que instaura a volição, podendo ser aquele que discursa (o candidato a primeiro ministro) ou um terceiro-reportado (indivíduo constituído no discurso pelo candidato a primeiro ministro); e (ii) o tipo de verbo no infinitivo que integra a construção.

No que diz respeito ao tipo de sujeito que emprega a construção, deve tratar-se de um ser capaz de volição e animado [+ humano], podendo ser: (i) o próprio candidato ou algum grupo no qual ele está inserido (primeira pessoa, yo e nosotros); (ii) a pessoa com quem o candidato dialoga (segunda pessoa, tú ou vosotros); ou (iii) um indivíduo em particular de quem o candidato reporta a volição (terceira pessoa, él, ella, usted, ellos, ellas, e ustedes).

Em relação ao tipo de verbo no infinitivo que integra a construção, temos: (i) verbos performativos, que conduzem a realização de uma ação de forma ativa sempre e quando se emite o enunciado (ROSSOWOWÁ, 2016); (ii) verbos dicendi, que introduzem um

${ }^{4}$ Os discursos de investidura foram retirados de páginas online da internet. Disponibilizamos os links de onde foram retirados os discursos de: Rodríguez Zapatero (15 de abril de 2004): <https://bit.ly/2CrGAjE>; Rodríguez Zapatero (08 de abril de 2008): <https://bit.ly/2IydptT>; Pedro Sánchez (01 de março 2016): <https://bit.ly/2GytNxQ>; Pedro Sánchez (04 de março 2016): <https://bit.ly/2q8RtPn>; Pedro Sánchez (31 de agosto 2016): <https://bit.ly/2nkvel8>. Acesso em: 20 dez. 2017. 
ato expositivo para manifestar o modo em que um dado argumento se encaixa naquilo de que se fala (FRÍAS LEBRON, 2012); e (iii) verbos cognitivos, que são relativos aos pensamentos, às crenças, às inferências, aos desejos, aos gostos, etc. (ALZATE, 2016).

Especificamente, para a construção querer+infinitivo, constatamos, em nosso córpus, que: (i) houve o emprego tanto da primeira pessoa do singular (yo) quanto da primeira pessoa do plural (nosotros); e (ii) houve escopo de verbos performativos, cognitivos e dicendi.

Em relação ao o tipo de sujeito sintático/semântico que emprega a construção, vejamos a Tabela 1:

Tabela 1: Frequência do tipo de sujeito sintático/semântico que emprega a construção

\begin{tabular}{c|c|c}
\hline Tipo de sujeito & Frequência & Porcentagem \\
\hline Primeira pessoa do singular & 33 & $61,1 \%$ \\
\hline Primeira pessoa do plural & 17 & $31,5 \%$ \\
\hline Terceira pessoa do plural & 04 & $7,4 \%$ \\
\hline
\end{tabular}

Como vemos na Tabela 1, houve uma preferência pelo uso da primeira pessoa do singular, o que já era esperado, tendo em mente que o discurso de investidura, ao ser proferido pelo candidato a primeiro ministro, há uma maior probabilidade de que ele manifeste aquilo que lhe parece desejável (primeira pessoa do singular) ou aquilo que é desejável por parte de seu partido (primeira pessoa do plural), marcando, dessa forma, a subjetividade no discurso e destacando o seu eu em relação aos demais candidatos. Vejamos (1) e (2):

(1) Quiero lograr un amplio acuerdo, porque creo que la educación requiere proyectos de largo plazo, estabilidad suficiente para evaluar sus resultados y un amplio consenso social que respalde la actividad de los docentes (D1)

[Quero conseguir um amplo acordo, porque acredito que a educação requer projetos de longo prazo, estabilidade suficiente para que sejam avaliados os resultados e um amplo consenso social que resguarde a atividade dos docentes]

(2) Por eso, queremos ofrecer a todas las fuerzas políticas un consenso básico para afrontar una reforma concreta y limitada de la Constitución que aborde esos problemas (D1)

[Por isso, queremos oferecer a todas as forças políticas um consenso básico para que se projete uma reforma concreta e limitada da Constituição que aborde esses problemas]

Em (1), vemos que o candidato instaura a volição por meio da construção querer+infinitivo para manifestar ao Parlamento Espanhol um desejo seu de "conseguir amplo acordo no que concerne à educação espanhola", levando-nos a inferir que o emprego da primeira pessoa (quiero), para a instauração da modalidade volitiva, refira-se a um estado-de-coisas controlado [+ controle] pelo candidato em relação à formulação de acordos para melhorar a educação, haja vista que "educação" e "saúde" são, à priori, atividades fim de um estado de direito. Em (2), temos que o candidato a primeiro ministro emprega a primeira pessoa do plural (queremos), também por meio da construção querer+infinitivo, para instaurar a modalidade volitiva em relação à "reforma da Constituição Espanhola", o que poderia ser um indício de que o candidato fale em nome de seu partido, haja vista que uma reforma na Constituição Espanhola requer um amplo apoio, não apenas dos demais membros de seu partido, como dos membros que compõem o Parlamento Espanhol.

Em relação ao tipo de verbo no infinitivo que acompanha o verbo querer, pudemos constatar, não apenas a presença de verbos performativos, mas também verbos cognitivos e dicendi. Vejamos a Tabela 2: 
Tabela 2: Frequência do tipo de verbo no infinitivo para a construção querer +infinitivo

\begin{tabular}{c|c|c}
\hline $\begin{array}{c}\text { Tipo de verbo no infinitivo } \\
\text { Verbo performativo }\end{array}$ & 29 & Frequência \\
\hline Verbo cognitivo & 19 & $53,7 \%$ \\
\hline Verbo dicendi & 6 & $35,2 \%$ \\
\hline Total & \multicolumn{2}{c}{$11,1 \%$} \\
\hline & Fonte: Elaborado pelos autores com base nos dados do SPSS
\end{tabular}

Como podemos verificar na Tabela 2, há uma maior incidência de verbos performativos, o que é um indicativo de que o falante expressa a intencionalidade de potencializar alguma ação política em seu futuro mandato, caso venha a ser eleito. Vemos também que há uma significativa presença de verbos cognitivos. Vejamos os verbos performativos que acompanham o verbo querer de (3) a (5):

(3) Con la misma voluntad, quiero instituir una Conferencia de Presidentes (D1)

[Com essa mesma vontade, quero instituir uma Conferência de Presidentes]

(4) [...] queremos aprobar una programación presupuestaria plurianual y reformar la jurisdicción militar para su homologación con el resto de órdenes jurisdiccionales. (D3)

[Queremos aprovar uma programação orçamentária plurianual e reformar a jurisdição militar para a sua homologação com o resto das ordens jurisdicionais]

Em (3), temos o emprego da construção querer+infinitivo, empregado na primeira pessoa do singular, em que o falante (candidato a primeiro ministro) manifesta em seu discurso a desejabilidade de "instituir uma Conferência de Presidentes" e "fazer um pronunciamento prévio". Em (4), vemos que o mesmo verbo, empregado na primeira pessoa do plural, é utilizado pelo falante para fazer referência às intenções de seu partido (implicatura de futuridade), o PSOE (Partido Socialista Obreiro Espanhol), em "aprovar uma programação orçamentária plurianual" e "reformar a jurisdição militar". Em (3) e (4), constatamos que a construção querer+infinitivo atua na camada da Propriedade Configuracional, haja vista que está relacionado às intencionalidades (desejabilidade) de um Indivíduo (um ser que deseja ou um grupo de pessoas que deseja), um Tempo (no caso, um tempo relativo, pois está relacionado a algo, que é desejado no momento da enunciação, mas que se potencializará em um dado momento futuro) e algumas Propriedades Lexicais que podem ser apenas avaliadas em termos de sua aplicabilidade a outros tipos de entidade. De acordo com Hengeveld e Mackenzie (2008), a Propriedade Configuracional não se caracteriza em termos de espaço e tempo, podendo ser apenas avaliada em termos de sua aplicabilidade a outros tipos de entidades ou a situação que ela descreve, dessa forma, não apresenta existência independente.

Com base em Oliveira (2017), verificamos, em (3) e (4), um caso de modalização volitiva com valor semântico de intenção, haja vista que, aquilo que é desejado pelo participante expresso no predicado, refere-se a algo por ele controlado [+ controle], de caráter mais subjetivo [+ subjetivo] por ainda encontrar-se no plano do pensamento, mas possível de vir a ser realizado [+ diretivo]. Para Hengeveld e Mackenzie (2008), tratar-se-ia de modalidade volitiva orientada-para-o-participante, haja vista que há a descrição do desejo do participante (candidato a primeiro ministro ou o partido que ele representa) de se engajar no evento que é descrito no predicado; em que o verbo querer+infinitivo funciona como um modalizador volitivo que atua na camada da Propriedade Configuracional (Nível Representacional). 
Nesses casos citados anteriormente, temos que o verbo querer atua como um verbo léxico e não como um verbo auxiliar propriamente dito, o que seria um indício de baixa gramaticalização conforme Hidalgo (2012), pois aquilo que o verbo querer escopa poderia, facilmente, ser comutado pelo emprego de algum pronome complemento direto:

(3) Con la misma voluntad, lo quiero.

(4) La queremos para su homologación con el resto de órdenes jurisdiccionales.

Passemos agora aos casos de verbos cognitivos que acompanham o verbo querer, vejamos de (5) a (8):

(5) Quiero, en este momento solemne, agradecer la entrega y dedicación de Jueces, fiscales, policías y guardias civiles. (D2)

[Quero, neste momento solene, agradecer a entrega e a dedicação de Juízes, fiscais, policiais e guardas civis]

(6) Quiero en primer lugar mostrar mi satisfacción personal y también la de mi Grupo Parlamentario por la celebración de este pleno y por lo que ello significa. Las instituciones democráticas de nuestro país vuelven a funcionar. (D4)

[Quero em primeiro lugar mostrar minha satisfação pessoal e também a satisfação do meu Grupo Parlamentar pela celebração desta seção plenária e pelo que isso significa. As instituições democráticas do nosso país voltam a funcionar]

(7) En cuanto a nuestra política de Defensa, queremos asegurar el compromiso de España en misiones de paz avaladas siempre por los organismos internacionales (D3)

[Em relação à nossa política de defesa, queremos garantir o compromisso da Espanha em missões de paz sempre aprovadas por organizações internacionais]

(8) Quiero comprometerme ante esta Cámara con algunas de aquellas peticiones de la Generalitat, que por otra parte, coinciden con peticiones de otras CCAA: financiación suficiente de la Ley de Dependencia, incremento del presupuesto para políticas activas de empleo, derogación de la Reforma Local, paralización de la LOMCE y recuperación de los fondos para el Programa de Desarrollo Rural. (D3)

[Quero comprometer-me ante esta Câmara com algumas daquelas petições da Generalitat (Governo da Catalunha), que por outra parte, coincidem com as petições de outras Comunidades Autônomas: financiamento suficiente da Lei de Dependência, incremento do pressuposto para políticas ativas de emprego, revogação da Reforma Local, paralização da LOMCE e recuperação dos recursos para o Programa de Desenvolvimento Rural]

De (5) a (8), temos que o verbo no infinitivo que integra a construção querer +infinitivo tratam-se de cognitivos: agradecer, mostrar, asegurar e comprometerse respectivamente. Nesses casos, não há, conforme Oliveira (2017), modalização volitiva, mas apenas marcas de polidez e cortesia, o que nos leva a entender que a construção querer+infinitivo não está atuando nas camadas do Nível Representacional, mas nas camadas de um nível mais acima do Componente Gramatical, isto é, nas camadas do Nível Interpessoal. Em relação à teoria da GDF, averiguamos que a construção querer+infinitivo, no que diz respeito aos casos de (5) a (8), integra Atos Discursivos, o que é possível, sabendo-se que um elemento lexical (no caso, o verbo querer que integra a construção perifrástica), com base em Hengeveld (2017), pode deslocar-se das camadas mais baixas para as camadas mais altas, sem seguir um fluxo contínuo.

Segundo Hengeveld e Mackenzie (2008, p. 04), o Ato Discursivo é "a menor unidade identificável de comportamento discursivo" ${ }^{5}$ apresentando algum valor discursivo dentro de uma dada situação de interação entre Falante e Ouvinte. Em (5) e (6), verificamos que a construção querer+infinitivo integra Atos Discursivos de tipo Expressivos, que, segundo os autores, referem-se à expressão dos sentimentos do falante; e que poderiam ser ditos da seguinte forma: "Agradeço a entrega e a dedicação de Juízes, fiscais, policiais e guardas civis" e "Revelo a minha satisfação pessoal e também a satisfação do meu Grupo Parlamentar". Por sua vez, em (7) e (8), constatamos que a construção querer+infinitivo integra Atos Discursivos do tipo Ilocutivos, que envolvem um Conteúdo Comunicado e uma ilocução lexical ou abstrata; e que poderiam ser proferidos da seguinte maneira: "Asseguro o compromisso da

${ }^{5}$ Tradução nossa. O original diz: "the smallest identifiable unit of communicative behavior" (HENGEVELD; MACKENZIE, 2008, p. 04). 
Espanha em missões de paz" e "Comprometo-me ante esta Câmara com algumas daquelas petições da Generalitat: financiamento suficiente da Lei de Dependência, incremento do pressuposto para políticas ativas de emprego, revogação da Reforma Local, paralisação da LOMCE e recuperação dos recursos para o Programa de Desenvolvimento Rural”.

Nos casos de (5) a (8), com base em Hidalgo (2012), podemos inferir que há um completo "esvaziamento semântico" do caráter volitivo da construção querer+infinitivo, como ocorre nos casos de imanência em língua espanhola, ${ }^{6}$ haja vista que a construção querer+infinitivo passa a funcionar como um elemento discursivo ao ser empregado pelo falante para manifestar polidez e cortesia. Ainda com base no autor, isso poderia ser um indício de gramaticalização desta construção, ainda que aquilo que o verbo querer escopa, possa ser comutado por um pronome, no caso, ello (isso), o que define, segundo Topor (2011), o verbo querer como um verbo semiauxiliar, a saber:

(5) quiero ello, en este momento solemne;

(6) quiero ello en primer lugar por la celebración de este pleno y por lo que ello significa;

(7) En cuanto a nuestra política de Defensa, queremos ello en misiones de paz avaladas siempre por los organismos internacionales;

(8) quiero ello ante esta Cámara con algunas de aquellas peticiones de la Generalitat, que por otra parte, coinciden con peticiones de otras CCAA.

No que diz respeito aos verbos dicendi, vejamos (9) e (10):

(9) Señorías, quiero decirlo claramente: para el gobierno de España la cultura no merece ser tratada como una mercancía más (D1)

[Senhorias, quero dizer isso claramente: para o governo da Espanha a cultura não merece ser tratada como mais uma mercadoria]

(10) Sea cual sea ese resultado, quiero resaltar hoy en esta tribuna que el PSOE se siente orgulloso de haber conseguido los objetivos que nos proponíamos al llegar hasta aquí. (D3)

[Seja qual for esse resultado, quero ressaltar hoje nesta tribuna que o PSOE se sente orgulhoso de haver conseguido os objetivos que nós havíamos proposto ao chegar até aqui]

Em (9) e (10), constatamos que a construção querer+infinitivo integra Atos Discursivos de tipo Ilocutivos, acompanhados de operadores e modificadores, no caso, hoy e claramente, respectivamente. O modificador claramente indica um estilo do Ato Discursivo e o operador hoy se refere a um tempo absoluto. Podemos dizer que esses Atos Discursivos dos quais a construção querer+infinitivo integra, estão diretamente relacionados às atitudes do falante com relação ao contexto em que os discursos de investidura são proferidos e na relação entre Falante (candidato a primeiro ministro) e Ouvinte (os demais membros do Parlamento Espanhol), em que a relevância enunciativa da construção querer+infinitivo (com os verbos cognitivos e os verbos dicendi) se constrói a partir do próprio contexto de interação. Nestes casos, há a impossibilidade de comutação daquilo que o verbo querer escopa por um pronome, no caso, ello (isso), sem que o enunciado adquirisse outro tipo de significado, sendo apenas possível a manutenção do significado original para a construção querer+infinitivo, como podemos averiguar:

(9) Señorías, quiero ello claramente: para el gobierno de España/Señorías, quiero decir ello claramente: para el gobierno de España; (10) Sea cual sea ese resultado, quiero ello hoy en esta tribuna/ Sea cual sea ese resultado, quiero resaltar ello hoy en esta tribuna.

Com base em Topor (2011) e Hidalgo (2012), podemos inferir que o verbo querer quando acompanhado de verbos dicendi no infinitivo, estaria funcionando como um verbo auxiliar, sendo a construção querer+infinitivo uma perífrase. Dessa forma, para os discursos de investidura analisados, comprovamos que a construção querer+infinitivo atua tanto em camadas mais baixas do Nível

\footnotetext{
${ }^{6}$ Nos casos de imanência, há um completo esvaziamento do valor semântico de volição da construção querer+infinitivo, por isso o verbo querer passa a ser entendido como um verbo auxiliar, o que, nas palavras de Hengeveld (2017), já que a perda das suas propriedades semânticas originais (expressão de volição) e passa a exercer funções discursivas, dependendo do contexto em que esta construção é utilizada pelo falante. Isso pode ser explicado, tendo em vista que o verbo querer passa a atuar em camadas mais altas dentro do Componente Gramatical.
} 
Representacional (Propriedade Configuracional) quanto em camadas mais altas do Nível Interpessoal (Ato Discursivo) em decorrência do uso. Vejamos o Quadro 7:

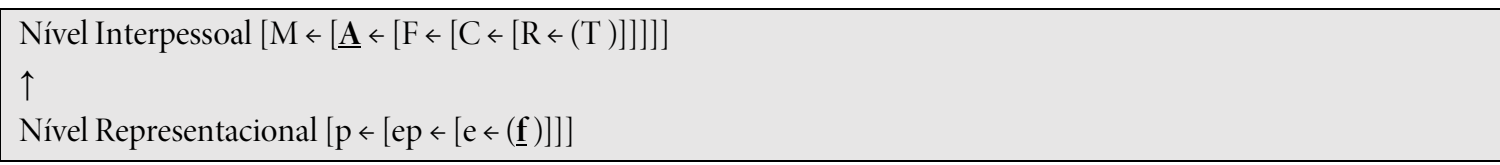

Quadro 7: Gramaticalização da construção querer+infinitivo no Componente Gramatical da GDF

Fonte: Elaborado com base em Hengeveld (2017)

Sabendo-se que a construção querer+infinitivo, nos discursos de investidura analisados, incidiu sobre a camada da Propriedade Configuracional (Nível Representacional) e na camada do Ato Discurso (Nível Interpessoal), poderíamos apontar uma possível grau gramaticalização dessa construção, considerando que ela poderia atuar como uma marca de futuridade (quando o querer escopa verbos performativos), ou um elemento discursivo para a marcação de polidez e cortesia (quando o querer escopa verbos cognitivos), ou como um sinalizador da relevância enunciativa construída a partir do próprio contexto de interação (quando o querer escopa verbos dicendi).

No Quadro 8, apresentamos uma síntese dos resultados encontrados:

Construção querer+infinitivo

\begin{tabular}{|c|c|c|}
\hline Querer+performativo & Querer+cognitivo & Querer+dicendi \\
\hline $\begin{array}{c}\text { Atua como um modalizador volitivo, } \\
\text { para a manifestação das } \\
\text { intencionalidades do falante }\end{array}$ & $\begin{array}{l}\text { Atua como um elemento discursivo para } \\
\text { a manifestação de polidez e cortesia }\end{array}$ & $\begin{array}{l}\text { Atua na manifestação da relevância } \\
\text { enunciativa daquilo que a construção } \\
\text { escopa, construída a partir do próprio } \\
\text { contexto de interação }\end{array}$ \\
\hline $\begin{array}{l}\text { O verbo querer atua como um verbo } \\
\text { léxico }\end{array}$ & $\begin{array}{l}\text { O verbo querer atua como um verbo } \\
\text { semiauxiliar }\end{array}$ & $\begin{array}{l}\text { O verbo querer atua como um verbo } \\
\text { auxiliar }\end{array}$ \\
\hline $\begin{array}{l}\text { Aquilo que o verbo querer escopa pode } \\
\text { ser comutado por um pronome }\end{array}$ & $\begin{array}{l}\text { Aquilo que o verbo querer escopa pode } \\
\text { ser comutado por um pronome }\end{array}$ & $\begin{array}{l}\text { Aquilo que o verbo querer escopa só } \\
\text { pode ser comutado por um pronome } \\
\text { desde que se mantenha o verbo no } \\
\text { infinitivo }\end{array}$ \\
\hline Mantém-se o valor semântico de volição & $\begin{array}{l}\text { Há um esvaziamento do valor semântico } \\
\qquad \text { de volição }\end{array}$ & $\begin{array}{l}\text { Há um esvaziamento do valor semântico } \\
\text { de volição }\end{array}$ \\
\hline
\end{tabular}

Quadro 8: Síntese da análise da construção querer+infinitivo

Fonte: Elaborado com base na análise dos autores

Em suma, temos que a construção querer+infinitivo quando composta de verbos performativos, faz com que esta construção atue como um modalizador volitivo, incidindo sobre a camada da Propriedade Configuracional (Nível Representacional), e estando a modalidade orientada-para-o-participante, em que o verbo querer comporta-se como um verbo léxico. Por sua vez, ao compor-se por verbos cognitivos e dicendi, a construção passa a incidir sobre as camadas mais altas dentro do Componente Gramatical (Nível Interpessoal), passando a atuar como um elemento discursivo, e o verbo querer, comportando-se, respectivamente, como um verbo semiauxiliar e auxiliar. 


\section{CONCLUSÃO}

Como vimos, os dados analisados da construção querer+infinitivo mostram que nos deparamos com um possível índice de gramaticalização em curso desta construção, na medida em que temos observado que esta construção pode atuar tanto em camadas mais baixas do Nível Representacional, no caso, na camada da Propriedade Configuracional, atuando como um modalizador volitivo, com orientação para o Participante; quanto em camadas mais altas do Nível Interpessoal, no caso, na camada do Ato Discursivo, em que esta construção atua como um elemento discursivo, em que a relevância enunciativa desta construção se constrói a partir do contexto de interação entre os participantes (Falante e Ouvinte).

Constatamos que, segundo Barreto e Souza (2016), Hengeveld (2017) e Souza (2017), ao se iniciar o processo de gramaticalização de um dado elemento linguístico, há a expansão do seu escopo funcional em relação às outras dimensões de organização da gramática, na medida em que esse dado elemento linguístico vai adentrando as camadas e os níveis de organização da gramática (Componente Gramatical). Dessa forma, o elemento linguístico torna-se mais gramatical, pois apresenta tanto mudanças de natureza formal quanto de conteúdo. No caso do verbo querer, que integra a construção querer+infinitivo, este pode atuar tanto como um verbo léxico (quando acompanhado de verbos performativos), quanto como um verbo semiauxiliar (quando acompanhado de verbos cognitivos) ou um verbo auxiliar (quando acompanhado de verbos dicendi).

\section{REFERÊNCIAS}

ALCONCHEL, J. L. G. La expresión de la modalidad en Apelación final de Cristóbal Colón al rey Fernando: códice español I de la biblioteca John Carter de la universidad de Brown. In: MARTIN, G (org.). Cahiers de linguistique et de civilisation hispaniques médiévales, Paris, 2004. p. 55-69. Disponível em: http://bit.ly/2CKS7Lf. Acesso em: 05 jan. 2018.

ÁLVAREZ, A.; CHUMACEIRO, I. El discurso de investidura en la reelección de Uribe y de Chávez. Revista Forma y Función, v. 22, n. 2, p. 13-42, 2009. Disponível em: https://bit.ly/2GmqmLh. Acesso em: 05 abr. 2018.

ALZATE, R. G. Los verbos de actitud proposicional como estrategias evidenciales en el español de Medellín. Revista Lingüística y Literatura, v. 13, n. 69, 2016, p. 339-361. Disponível em: https://bit.ly/2q8goCr. Acesso em: 05 abr. 2018.

BARRETO, K. E. S.; SOUZA, E. R. F. A gramaticalização de no caso de no português brasileiro: um enfoque discursivo-funcional. Guavira Letras Três Lagoas, v. 1, n. 22, p. 80-104, 2016. Disponível em: http://bit.ly/2m24fNc. Acesso em: 05 jan. 2018.

CASSEB-GALVÃO, V. Gramática discursivo-funcional e teoria da gramaticalização: revisitando os usos de [diski] no português brasileiro. Revista de Filologia e Linguística Portuguesa, v. 13, n. 2, p. 305-335, 2011. Disponível em: https://bit.ly/2usfPbL. Acesso em: 05 jan. 2018.

ESTEBAN, R. A. El discurso de investidura como instrumento de comunicación política en España (1979-2008). Revista Internacional de Investigación en Comunicación, n. 4, 2011. Disponível em: http://zip.net/brtsCc. Acesso em: 02 jul. 2016.

FARÍAS LEBRÓN, M. T. Sobre las formas de reproducción del discurso ajeno en algunos textos periodísticos de la prensa italiana y española. Revista Philologia Hispalensis, v. 26, n.3, 2012, p. 121-153. Disponível em: https://bit.ly/2q839BB. Acesso em: 05 abr. 2018.

FURTAdo DA CUnHA, M. A. Funcionalismo. In: MARTELOTTA, M. E. (org.). Manual de Linguística. São Paulo: Editora Contexto, 2009. p. 157-176.

GIVON, T. Syntax: a functional-typological introduction. New York: Academic Press, 2001.

Oliveira \& Prata Intenção, polidez e relevância enunciativa: gramaticalização na construção querer+infinitivo. 
GÓMEZ TORREGO, L. Perífrasis verbales con infinitivo: valores y usos en la lengua hablada. Madrid: Arco Libros, 2009.

GRAMÁTICA DE LA REAL ACADEMIA ESPAÑOLA. Madrid: Espasa Libros, 2010.

HENGEVELD, K. A hierarchical approach to grammaticalization. In: HENGEVELD, K., NARROG, H., OLBERTZ, H. The Grammaticalization of Tense, Aspect, Modality, and Evidentiality from a Functional Perspective. Berlin: Gruyter Mouton, 2017. p. 122.

HENGEVELD, K.; MACKENZIE, J. L. Functional Discourse Grammar: a typologically based theory of language structure. Oxford: Oxford Linguistics, 2008.

HIDALGO, M. J. Tiempo y lenguaje: restricciones cognitivo-fenomenológicas en la evolución de las formas de futuro. Santiago do Chile. 2012. 240f. Tese (Doutorado em Estudos Cognitivos) - Faculdade de Filosofia e Humanidades, Universidade do Chile, Santiago, 2012. Disponível em: http://zip.net/bgtG3h. Acesso em: 30 mar. 2017.

MARTÍNEZ, F. P.; MANZANO, P. G.; BARRIENDOS, M. S. Presente, ir+a+infinitivo y futuro: ¿expresan lo mismo cuando se habla del futuro. Centro Virtual Cervantes, v. 25, n. 1, p. 668-674, 2004. Disponível em: http://bit.ly/2EbDkFE. Acesso em: 05 jan. 2018.

OLIVEIRA, A. S. Modalidade volitiva em língua espanhola nos discursos do Papa Francisco em viagem apostólica. 2017. $310 \mathrm{f}$. Dissertação (Mestrado em Linguística) - Programa de Pós-Graduação em Linguística. Universidade Federal do Ceará (UFC), Fortaleza, 2017. Disponível em: http://bit.ly/2odUwqY. Acesso em: 14 dez. 2017.

OLIVEIRA, A. S.; NOGUEIRA, M. T; PRATA, N. P. P. A modalidade volitiva em língua espanhola: uma análise funcionalista em discursos de investidura. In: PRATA, N. P. P. et al. Espanhol em Pauta: perspectivas teórico-analíticas. Curitiba: Editora Appris, 2017. p.59-71.

ROSSOWOWÁ, L. Cortesía verbal en el español del siglo XIX. 2016. 195f. Dissertação (Mestrado em Filosofia) - Programa de PósGraduação em Filosofia, Universidade da Tchecoslováquia, Tchecoslováquia, 2016. Disponível em: https://bit.ly/2qdru8G. Acesso em: 05 abr. 2018.

SOUZA, C. N. Gramática Discursivo-Funcional, gramaticalização e Modalização. Revista de Estudos da Linguagem, v. 25, n. 4, p. 2095-2126, 2017. Disponível em: http://bit.ly/2Cvp3TC. Acesso em: 05 jan. 2018.

SOUZA, E. R. F. Gramaticalização dos itens lingüísticos assim, já e aí no português brasileiro: um estudo sob a perspectiva da Gramática Discursivo-Funcional. 2009. 260f. Tese (Doutorado em Linguística) - Programa de Pós-Graduação em Linguística, Universidade de Campinas, Campinas, 2009. Disponível em: http://bit.ly/2qzFwVB... Acesso em: 05 jan. 2018.

TOPOR, M. Perífrasis verbales del español y rumano un estudio contrastivo. 2011. 722f. Tese (Doutorado em Linguística) - Programa de Pós-Graduação em Linguística, Universidade de Lleida, Lleida, 2011. Disponível em: http://zip.net/bktsjX. Acesso em: 18 mar. 2016.

\section{(๑) $\circledast \circledast$}

